
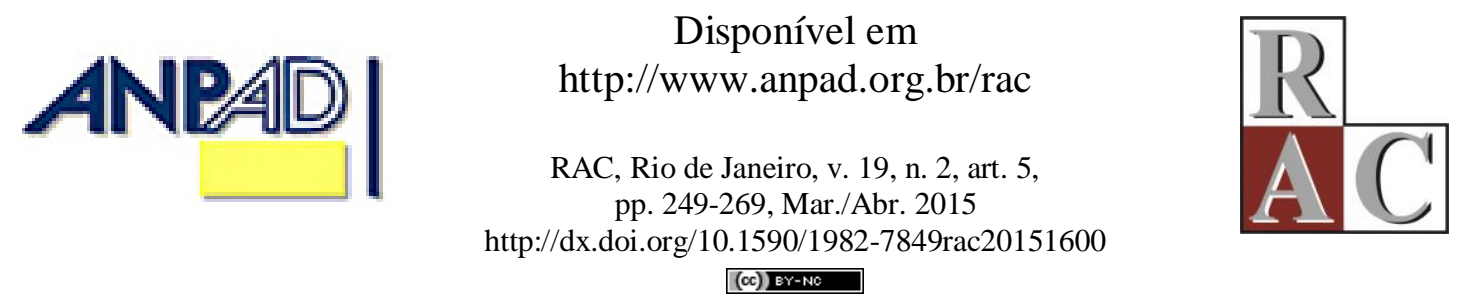

\title{
Estrutura de Capital e Remuneração dos Funcionários: Evidência Empírica no Brasil
}

Capital Structure and Staff Salary: Empirical Evidence in Brazil

Duk Young Choi Itaú Unibanco; Fundação Getulio Vargas - FGV/EAESP

Richard Saito Fundação Getulio Vargas - FGV/EAESP

Vinicius Augusto Brunassi Silva Fundação Getulio Vargas - FGV/EAESP

Artigo recebido em 08.08.2013. Última versão recebida em 17.06.2014. Aprovado em 15.07.2014. 


\title{
Resumo
}

Este artigo analisa se uma empresa com maior alavancagem financeira implica que seus funcionários demandem maiores salários dado o risco de financial distress. Utilizando o modelo de Berk, Stanton e Zechner (2010), foi aplicada uma regressão de dois estágios para uma amostra de 250 empresas não financeiras listadas na BOVESPA de 2007 a 2009. De fato, encontrou-se que, para cada $1 \%$ de alavancagem financeira incremental, a remuneração dos funcionários aumenta em 0,26\%, mesmo controlando para o perfil do Chief Executive Officer (CEO).

Palavras-chave: estrutura de capital; remuneração; aversão a risco; economia do trabalho.

\begin{abstract}
This paper analyzes whether the higher the company's financial leverage, the higher the salaries demanded by staff for the embedded financial distress risk. By applying Berk, Stanton and Zechner's (2010) model, we use a $2 S L S$ for a sample of 250 non-financial companies listed on BOVESPA from 2007 to 2009. Indeed, we find that for each additional $1 \%$ of financial leverage, the staff remunerations increase by $0.26 \%$, controlling for Chief Executive Officer (CEO) profile.
\end{abstract}

Key words: capital structure; wage; risk aversion; labor economics. 


\section{Introdução}

Desde o trabalho clássico de Modigliani e Miller (1958), teorias foram apresentadas e evidências empíricas constatadas com o propósito de explicar os determinantes da estrutura de capital. Em estudo publicado recentemente, Berk, Stanton e Zechner (2010) expõem uma nova abordagem que relaciona diretamente a aversão ao risco dos trabalhadores com o benefício proporcionado pelo endividamento. Com a obrigação da publicação da Demonstração do Valor Adicionado (DVA) a partir de 2007 e a adoção do Formulário de Referência a partir de 2009, viabilizou-se o estudo empírico do modelo de Berk et al. (2010) para o Brasil, uma vez que é possível realizar o cálculo da remuneração média dos funcionários.

De acordo com Linn, Sandiffer e Stein (1985), são os funcionários que sofrem consequências mais graves quando uma empresa passa por dificuldades financeiras ou, eventualmente, encerra suas atividades, com impactos sociais além de individuais. Para evitar tais mudanças, trabalhadores ficam entricheirados e tendem a influenciar a estrutura de capital, segundo Novaes e Zingales (1995), ou exigem uma recompensa para trabalhar em empresas de maior risco, de acordo com Chang (1992) e Jaggia e Thakor (1994). Esta exigência, por parte dos funcionários, de aumento da compensação pelo trabalho é um custo gerado pelo capital humano, que afeta o nível de alavancagem da empresa.

O objetivo deste artigo é verificar, seguindo a abordagem de Berk et al. (2010), se as hipóteses referentes à aversão ao risco dos trabalhadores possuem impacto na estrutura de capital das empresas brasileiras. Das cinco hipóteses feitas pelo modelo de Berk et al. (2010), este estudo verificará quatro: (a) empresas mais arriscadas preferem ter alavancagem menor; (b) empresas mais alavancadas pagam maior salário para contratar trabalhadores; (c) empresas mais intensivas em capital pagam salário maior, controlando tal efeito pela rentabilidade; (d) a correlação entre grau de aversão a risco dos trabalhadores e alavancagem financeira das empresas em que trabalham pode auxiliar na explicação do endividamento.

A análise empírica foi realizada por meio de regressão agrupada de dois estágios, em que os resultados do primeiro estágio foram utilizados para estimar alavancagem e resolver problemas de endogeneidade.

Os resultados contribuem para a literatura empírica que estuda estrutura de capital ao incluir como os funcionários possuem remuneração alinhada com o risco percebido do negócio. Além disso, afere-se que as pessoas são influenciadas pelos riscos da empresa, além de também influenciar, de acordo com suas características, as políticas da organização. Adicionalmente, este estudo corrobora os resultados apresentados por S. C. Myers e Majluf (1984), Graham (1996) e Jensen (1986) para empresas brasileiras.

Este artigo está organizado da seguinte forma: primeiro, exploramos os trabalhos que serviram de base para o desenvolvimento deste estudo e para a formulação da hipótese de pesquisa. Em seguida, descrevemos a base de dados e a metodologia de pesquisa. Por último, apresentamos os resultados e concluímos o artigo.

\section{Estrutura de Capital: Relação da Alavancagem e Remuneração}

Desde o artigo de Modigliani e Miller (1958), pesquisadores analisam os fatores que afetam a estrutura de capital das empresas (Chen \& Zhao, 2006; S. C. Myers, 1977; Titman \& Wessels, 1988). Num mundo sem fricções, a estrutura de capital é irrelevante para o valor da empresa e, portanto, não deveria existir uma preferência por determinado tipo de estrutura de capital (Modigliani \& Miller, 1958). Porém, no mundo real, cada empresa pode optar por um grau diferente de alavancagem.

A abordagem empírica em finanças apresenta que o uso de dívida seja benéfico para as empresas em virtude da redução do custo de capital devido ao benefício fiscal trazido pelo pagamento de juros. 
Há evidências empíricas de que as empresas realmente usam a dívida com esta finalidade fiscal e que esta prática adiciona valor para as empresas. Graham (1996) mostrou que as empresas com maior alíquota de imposto de renda utilizam a dívida com maior intensidade em comparação às demais.

No entanto, apesar desses benefícios, principalmente o fiscal, as empresas preferem optar pelo uso do capital próprio, mesmo este sendo mais caro do que a dívida. Esta preferência pelo capital aparentemente mais caro intrigou muitos pesquisadores, que o apelidaram de capital structure puzzle (S. C. Myers, 1984). Por exemplo, o custo mais visível do uso da dívida, o de falência, é pequeno comparado com seu benefício fiscal (Titman, 1984; Weiss, 1990). De acordo com a teoria de pecking order (S. C. Myers, 1984; S. C. Myers \& Majluf, 1984), as empresas preferem se financiar usando, primeiro, os recursos gerados internamente, depois, dívida, e, por fim, emitindo novas ações. S. C. Myers (1984) sugere que a hierarquia de recursos captados ocorra devido à assimetria informacional.

Almeida e Philippon (2007) desenvolveram uma metodologia usando o spread por default entre bonds corporativos e T-bonds, calculando o custo da dificuldade financeira ex-ante, ajustado ao risco. Os autores chegaram à conclusão de que este custo pode ser tão grande quanto o benefício fiscal da dívida, calculado por Graham (2000), o que explicaria a relutância das empresas em usar dívida com maior intensidade. Além dos custos citados, há muitos outros que justificam o capital structure puzzle, mas um custo que vem se destacando é o de capital humano. Segundo Jaggia e Thakor (1994) e Berk et al. (2010), o custo de capital humano consiste em aumento da remuneração dos funcionários por causa do aumento do risco de falência e, consequentemente, a da perda de emprego, causada pelo aumento da alavancagem financeira.

O estudo sobre a relação entre alavancagem e remuneração dos funcionários não é algo novo. As pesquisas de Chang $(1992,1993)$ com foco no papel da alavancagem como meio de transferência da riqueza entre acionistas e empregados mostram que a alavancagem tem relação negativa com remuneração, reforçando o benefício do uso da dívida nas empresas. Outro estudo que relaciona remuneração com decisão sobre estrutura de capital é o de Jaggia e Thakor (1994). Os autores derivaram o modelo que explica como a aversão ao risco dos funcionários afeta a decisão sobre a estrutura de capital das empresas. Berk et al. (2010) desenvolveram um modelo de contrato de trabalho otimizado que considera a aversão ao risco dos empregados afetando a estrutura de capital. O modelo prevê alguns resultados: (a) Sob alíquota de imposto realista, o grau de alavancagem é moderado, resultando na subutilização do benefício fiscal; (b) A diferença na aversão ao risco dos trabalhadores nas empresas implica a diferença de alavancagem; (c) As empresas mais alavancadas pagam maior salário para contratar novos trabalhadores; (d) Controladas pela rentabilidade, as empresas mais intensivas em capital pagam salário maior; (e) Empresas mais arriscadas preferem ter alavancagem menor.

Chemmanur, Cheng e Zhang (2013) testaram empiricamente as hipóteses de Berk et al. (2010) em empresas americanas, no período entre 1981 e 2006, e concluíram que o aumento salarial causado pelo aumento da alavancagem pode ultrapassar o valor do benefício fiscal em algum ponto, o que pode explicar o receio das empresas em usar dívida intensivamente. No modelo de Berk et al. (2010), o nível ótimo da alavancagem decresce de acordo com o aumento da aversão ao risco dos funcionários e da volatilidade da produtividade. Como a volatilidade da produtividade está ligada ao risco, isto significa que, ceteris paribus, as empresas mais arriscadas, ou cujos funcionários possuem maior aversão ao risco, têm o nível ótimo de alavancagem menor. A hipótese de que empresas mais arriscadas preferem ter alavancagem menor é intuitiva (Rajan \& Zingales, 1995; Titman \& Wessels, 1988), embora estudos empíricos tenham resultados variados.

De acordo com o modelo de Berk et al. (2010), o aumento nos gastos com a remuneração dos funcionários, causado pelo aumento da alavancagem, é maior para as empresas intensivas em mão de obra em termos comparativos com empresas intensivas em capital, pois a proporção de despesa com mão de obra é muito maior nas primeiras do que nas últimas. No entanto, as empresas intensivas em mão de obra, já cientes deste efeito, diminuem a alavancagem. Assim, empresas intensivas em capital, com custo de capital humano menor, conseguem alavancar mais. $\mathrm{O}$ modelo dos pesquisadores ainda mostra que empresas com maior alavancagem pagam maior salário para compensar o risco da perda de emprego. Mesmo que os funcionários não saibam calcular a alavancagem diretamente, eles ficariam 
cientes da probabilidade de sobrevivência da empresa por meio de outras informações, tais como o rating da empresa. A ideia de que os trabalhadores devem ser compensados com salário maior pelo risco, seja de acidente, seja da perda de emprego ou de outra natureza, vem da teoria dos salários hedônicos, da economia do trabalho, já bastante antiga (Ehrenberg, 1989; Esteves, 2008a, 2008b; Viscusi,1978). Segundo esta teoria, os trabalhadores estariam dispostos a trocar utilidade (salário) para reduzir não utilidade (risco no trabalho) a fim de maximizar a utilidade líquida.

O ponto de partida do modelo de Berk et al. (2010) é a aversão ao risco do agente, pois os autores assumem no modelo que o agente possui aversão ao risco, e o investidor neutralidade ao risco. Assim, é preciso entender a relação das características dos trabalhadores e sua aversão ao risco. Entre várias características individuais, praticamente todas as pesquisas (Hryshko, Luengo-Prado, \& Sorensen, 2008; Jianakoplos \& Bernasek, 1998; Morin \& Suarez, 1983; Palsson, 1996) apontam a idade como um determinante do risco individual e, em geral, ela tem correlação positiva com a aversão ao risco, principalmente financeiro. A hipótese de aversão ao risco de ciclo de vida explica que quanto mais longe da aposentadoria estiver a pessoa, mais ela consegue compensar qualquer perda financeira por meio da renda do trabalho e, portanto, possuirá menor aversão ao risco financeiro.

De acordo com Palsson (1996) e Jianakoplos e Bernasek (1998), o sexo também é importante. As pesquisas apontam que mulheres, em geral, possuem maior aversão ao risco, com resultados diferentes de acordo com a idade. A educação é mais uma variável que interferiria na aversão ao risco. A aversão ao risco aumenta com o nível educacional, independente do sexo (Jianakoplos \& Bernasek, 1998).

O investimento em capital pode ser realizado através do desenvolvimento das aptidões pessoais dos colaboradores de uma empresa. Embora o principal foco desta pesquisa seja estudar o aumento nos gastos com a remuneração dos funcionários, causado pelo aumento da alavancagem, é importante destacar outro componente do capital humano utilizado neste estudo e medido como grau de escolaridade. Segundo Becker (1964), o capital humano é formado por investimentos na melhoria produtiva e na ampliação de conhecimentos de um indivíduo.

Balassiano, Seabra e Lemos (2005) enfatizam que o investimento em educação apresenta ganhos de produtividade ao trabalhador e pode explicar diferenças na remuneração e no acesso a oportunidades no mercado de trabalho. Ehrlich, Hamlen e Yin (2008) analisam capital humano como um estoque de conhecimento que aumenta o fluxo de salários e a eficiência na gestão de ativos.

Para estudar a relação entre aversão ao risco, características individuais dos executivos e políticas de alavancagem e de investimento das empresas, Graham, Harvey e Puri (2012) usaram um teste psicométrico e aplicaram questionário aos executivos das empresas americanas. O resultado indicou uma relação positiva e forte entre aversão ao risco e idade. Contudo os efeitos na estrutura de capital não foram conclusivos.

No Brasil, não foi identificada a verificação das hipóteses previstas por Berk et al. (2010) analisadas conjuntamente por outros autores. A maioria dos estudos brasileiros relacionados à estrutura de capital foca o estudo empírico, testando a validade de teorias como trade-off (Brito \& Lima, 2005; Medeiros \& Daher, 2005) e os resultados de pecking order (Silva \& Brito, 2005). Outros estudos centralizam-se nos testes de determinantes da estrutura de capital no Brasil (Bastos, Nakamura, \& Basso, 2009; Gomes \& Leal, 2001; Nakamura et al., 2007; Rocha \& Amaral, 2007; Terra, 2002), endividamento e custo de agência (Kayo \& Famá, 1997), práticas de governança corporativa como determinantes da alavancagem (Silveira, Perobelli, \& Barros, 2008), relação entre o grau de internacionalização e alavancagem (Hiramoto \& Saito, 2010) e revisão teórica, como Matsuo, Rochman e Eid (2008), entre outros. Portanto, acredita-se que este estudo corrobora a análise da estrutura de capital das empresas brasileiras através da aplicação da abordagem de Berk et al. (2010). 


\section{Base de Dados, Variáveis de Estudo e Metodologia}

Os dados coletados foram obtidos diretamente do site da Comissão de Valores Mobiliários (CVM). Foram coletados os relatórios de todas as empresas não financeiras que estão listadas na Bovespa. Os relatórios coletados foram: Balanço Patrimonial; Demonstração de Resultados; Demonstração de Fluxo de Caixa; Demonstração de Mutação de Patrimônio Líquido e Demonstração do Valor Adicionado. A amostra deste estudo foi composta de 250 empresas, cujos dados de 55 empresas foram obtidos em 2007, de 98 empresas, em 2008, e de 97 empresas, em 2009.

Como esta pesquisa visava estudar as empresas típicas não financeiras e que desempenham atividade econômica real, foram excluídas empresas de tarifas reguladas, empresas com menos de cinco anos de cadastro, visto que não foi possível calcular a volatilidade da rentabilidade, e empresas com menos de mil funcionários, para ser condizente com estudos anteriores que apresentaram negociação coletiva entre empresa e funcionários, B. W. Myers e Saretto (2011). Para estudar o efeito dos determinantes do risco na estrutura de capital das empresas brasileiras, foi necessário obter as características individuais dos executivos brasileiros, principalmente dos Chief Executive Officer (CEO).

Os dados sobre as características dos executivos está disponível no IAN, no Grupo 2 - Tabela 2 - Experiência Profissional e Formação Acadêmica de cada conselheiro (Administração e Fiscal) e diretor. Neste caso, a coleta foi manual pelo fato deste documento não ter um padrão específico. Os itens coletados foram: idade, sexo, educação (medida em anos de estudo), MBA (se fez ou não), reputação da universidade onde fez graduação (medida de acordo com o IGC do Ministério de Educação) e área de formação. Foram coletados dados sobre 182 CEOs de 150 empresas entre 2004 e 2008, resultando em 434 observações, em que 65 foram em 2004, 76, em 2005, 94, em 2006, 95, em 2007 e 104 observações em 2008.

Embora o Balanço Social apresente dados sobre remuneração dos funcionários em detalhe, são poucas as empresas que publicam tal informação. Como não foi possível obter diretamente a remuneração dos funcionários, foi necessário utilizar a despesa com pessoal como uma proxy de remuneração dos funcionários, que está disponível na Demonstração do Valor Adicionado, obrigatório para as empresas brasileiras desde o exercício de 2008. Por meio deste relatório, dados de 2007, 2008 e 2009 puderam ser coletados. Outro dado necessário para calcular a despesa média com funcionários é o número total de funcionários, que foi obtido a partir do formulário de referência da CVM, que substituiu o antigo (IAN) e é bem mais abrangente.

Devido à obrigatoriedade do formulário ter início a partir do exercício de 2009, apenas os dados das empresas ativas no exercício de 2009 foram coletados. Pelas normas contábeis, seria correto relatar de forma consolidada, incluindo os dados das empresas subsidiárias, tanto o número de funcionários quanto a despesa com funcionários. Porém algumas empresas não relataram corretamente a quantidade de funcionários, o que causa distorção na remuneração média relatada. Para minimizar este erro, foi eliminada a despesa média menor que cinco mil e maior que 300 mil reais. Para amenizar o problema de assimetria na distribuição, os cálculos deste estudo foram feitos com a utilização do logaritmo natural da variável remuneração média.

No que se refere às variáveis explicativas, entre várias medidas de alavancagem, cada uma com suas vantagens e desvantagens (Rajan \& Zingales, 1995), este estudo buscou utilizar a dívida total contábil sobre capital total. A fórmula da alavancagem é demonstrada no decorrer desse artigo. As dívidas de curto prazo incluem: (a) Financiamentos bancários com o vencimento dentro de um ano; (b) Debêntures com o vencimento dentro de um ano; e (c) Obrigações tributárias com o vencimento dentro de um ano, excluindo as recorrentes como (ICMS), (IPI), (PIS), (COFINS), (INSS) e (FGTS). As dívidas de longo prazo incluem: (a) Financiamentos bancários com vencimento superior a um ano; (b) Debêntures com vencimento superior a um ano; e (c) Obrigações tributárias com vencimento superior a um ano. $\mathrm{O}$ efeito tamanho-salário, que indica que o tamanho da empresa está positivamente relacionado 
à remuneração, é um fenômeno documentado e explicado por vários autores, tanto nos EUA (Masters, 1969; Oi \& Idson, 1999) quanto no Brasil (Gatica, Mizala, \& Romaguera, 1995).

Este efeito também é um importante determinante da alavancagem (Fama \& French, 2002). As cinco proxies de tamanho da firma mais utilizadas são: faturamento, número de funcionários, valor de mercado da empresa, tamanho do patrimônio líquido e tamanho do ativo total. O tamanho é uma das variáveis explicativas mais importantes nos estudos financeiros sobre empresas e está relacionado tanto ao salário (efeito tamanho) quanto à alavancagem (Fama \& French, 1998, 2002; Oi \& Idson, 1999).

Existem várias representações para medir produtividade e todas elas dependem dos dados relatados pelas empresas. No estudo empírico com dados americanos, apresentado por Chemmanur et al. (2013), os autores utilizaram o faturamento médio por funcionário como proxy de produtividade. No entanto esta abordagem apresenta limitações por ignorar a questão da terceirização. A terceirização aumenta a saída (a venda), mas diminui a entrada (número de funcionários). Para resolver esta distorção, é aceitável utilizar a produtividade tendo como base o valor adicionado. O valor adicionado é a medida que expressa a riqueza criada pela empresa no período. Como as despesas com serviços terceirizados e com leasing operacional são descontadas para se obter o valor adicionado, elimina-se a distorção, chegando a um valor mais consistente com a produtividade dos funcionários com vínculos diretos.

O Market-to-Book foi usado como proxy para oportunidade de crescimento da firma. Como o valor de mercado é composto pelo valor presente das oportunidades de crescimento futuro e pelo patrimônio líquido, quanto maior for o valor de mercado da empresa em relação ao valor contábil de seu patrimônio líquido, maior é o valor presente da oportunidade de crescimento futuro. Este é calculado dividindo a capitalização do mercado pelo patrimônio líquido (seção 2.05), o valor contábil do capital próprio.

A variável intensidade do capital físico mede o nível de utilização dos recursos físicos e é calculada dividindo o ativo imobilizado pelo ativo total. O ativo imobilizado representa o bem de capital da empresa utilizado para produção e para atender clientes, caracterizando capital físico, cuja proporção em relação ao ativo total representa a dependência da empresa neste tipo de capital e, portanto, esta é uma medida importante por estar diretamente relacionada aos objetivos e as hipóteses deste estudo.

A volatilidade do lucro operacional é uma proxy para risco de negócio da firma e é diferente do risco financeiro, representado pela alavancagem. Muitos estudos antigos não separam estes riscos, mesmo sendo de natureza e origem diferentes. O desvio padrão do EBIT dividido pelo ativo total nos últimos cinco exercícios foi utilizado como proxy para volatilidade do lucro operacional. As variáveis alavancagem, tamanho, produtividade, market-to-book, intensidade de capital físico e volatilidade do lucro operacional são definidas como variáveis explicativas da variável remuneração. Lemmon, Roberts e Zender (2008) acreditam que as empresas tendem a manter sua estrutura capital por muito tempo. Esta variável apresenta razoável poder de explicação sobre o nível de alavancagem atual, ou seja, a alavancagem atual é escolhida com base na alavancagem passada.

A proxy para alavancagem-alvo das empresas é a alavancagem média do setor, que é utilizada como benchmark. Por este motivo, maior alavancagem para o setor, implica em maior alavancagem para a empresa. Assim, esperava-se que a alavancagem do setor mostrasse relação positiva com a alavancagem da empresa.

A rentabilidade passada é um fator importante para a decisão sobre a estrutura de capital da empresa, pois permite que a necessidade de capital seja suprida internamente. Por isso, a rentabilidade do ano anterior foi utilizada no modelo para estimar alavancagem. Como proxy para rentabilidade, foi utilizado o indicador EBITDA relativo ao ativo total.

A variável dividendo também participa do modelo devido ao mecanismo conhecido como substituição entre dívida e dividendos (Agrawal \& Jayaraman, 1994; Jensen, 1986). De acordo com os estudos, esperava-se que a alavancagem financeira estivesse positivamente relacionada ao pagamento de dividendos. No Brasil, empresas de capital aberto são obrigadas a pagar pelo menos $25 \%$ do lucro líquido em forma de dividendos, segundo a Lei $\mathrm{n}^{\circ} .6404$ (1976). Além dos dividendos, as empresas 
brasileiras podem remunerar seus acionistas por meio de juros sobre o capital próprio (JCP), um mecanismo criado pela Lei $\mathrm{n}^{\circ} .9249$ (1995) para remunerar os acionistas. Como ele representa uma remuneração aos acionistas, também, foi considerado como cálculo de dividendos.

A variável para o modelo é binária e indica se a empresa pagou mais do que o obrigatório ou não. Na Tabela 1, elenca-se a estatística descritiva das principais variáveis do estudo.

Tabela 1

Estatística Descritiva das Variáveis Explicativas

\begin{tabular}{lcccccc}
\cline { 2 - 7 } & Amostra & $\begin{array}{c}\mathbf{1 \%} \\
\text { Cutoff }\end{array}$ & Mediana & $\begin{array}{c}\mathbf{9 9 \%} \\
\text { Cutoff }\end{array}$ & Média & $\begin{array}{c}\text { Desvio } \\
\text { Padrão }\end{array}$ \\
\hline Número de Funcionários & 250 & 1065 & 4479,5 & 114059 & 11153,13 & 18690,25 \\
Remuneração Média & 250 & 14,6359 & 38,37504 & 195,6739 & 47,03383 & 32,64027 \\
Payout & 243 & $-0,0293085$ & .298789 & 1,659842 & .3743189 & .5119957 \\
Produtividade & 250 & 23,1282 & 120,932 & 1934,807 & 222,5461 & 295,0548 \\
Alavancagem & 250 & .0256285 & .4650979 & .9342459 & .4674925 & .2063632 \\
Alavancagem Média do Setor & 250 & .1790328 & .4426424 & .7500273 & .4476251 & .0961904 \\
Ativo Total & 250 & 199374,9 & 1806745 & $2,31 \mathrm{E}+08$ & $1,00 \mathrm{E}+07$ & $3,66 \mathrm{E}+07$ \\
Market-to-Book & 232 & .3313949 & 1,755701 & 19,50263 & 2,820539 & 3,690972 \\
Rentabilidade & 250 & $-0,1340619$ & 0,086389 & 0,3389855 & 0,098677 & 0,0864419 \\
Intensidade de Capital Físico & 250 & 0,0073457 & 0,327246 & 0,8366639 & 0,335129 & 0,2045681 \\
Volatilidade da Rentabilidade & 250 & 0,0083964 & 0,042167 & 0,1919392 & 0,053727 & 0,0666231 \\
Alíquota de IR & 244 & $-3,253923$ & $-0,2715$ & 1,511218 & $-0,31624$ & 0,7308439 \\
Valor no Mercado & 232 & 65600 & 1552830 & $2,70 \mathrm{E}+08$ & $1,14 \mathrm{E}+07$ & $4,64 \mathrm{E}+07$ \\
\hline
\end{tabular}

Nota. A Tabela 1 descreve as variáveis usadas no estudo da relação entre a alavancagem e a remuneração com todos os dados consolidados. Remuneração média é calculada dividindo a despesa com o pessoal pelo número de funcionários. A variável Payout é calculada dividindo a soma do dividendo e de juros sobre capital próprio pelo lucro líquido. Produtividade é calculada dividindo o valor adicionado total por número de funcionários. Alavancagem é calculada dividindo a soma das dívidas de longo e curto prazo pela soma das dívidas com o patrimônio líquido. Alavancagem média do setor é a alavancagem média do setor ao qual a empresa pertence, segundo a classificação setorial da EconomaticaTM. Market-to-book é calculada dividindo o valor da empresa no mercado pelo patrimônio líquido. Rentabilidade é calculada dividindo (EBITDA) pelo ativo total. Intensidade de capital físico é calculada dividindo ativo imobilizado pelo ativo total. Volatilidade da rentabilidade é o desvio padrão do (EBIT) dividida pelo ativo total nos últimos cinco exercícios. Alíquota de IR é calculada dividindo o imposto de renda pago no exercício pelo lucro líquido do exercício. Fonte: Elaboração própria.

Com base no referencial teórico e utilizando a definição das variáveis apresentadas, buscou-se aferir as seguintes hipóteses para este estudo:

H1: Empresas mais arriscadas preferem ter alavancagem menor.

H2: Controladas pela rentabilidade, as empresas mais intensivas em capital pagam salário maior.

H3: As empresas mais alavancadas pagam maior salário para contratar trabalhadores.

H4: A diferença na aversão ao risco dos trabalhadores nas empresas resulta nas diferenças de alavancagem.

Para testar as hipóteses 1, 2 e 3 foi utilizada uma regressão agrupada (pooled regression) de dois estágios, com o erro padrão corrigido pelo método de White (1980). No primeiro estágio, a alavancagem é estimada utilizando variáveis instrumentais. Por meio da análise do resultado, é possível confirmar a 
hipótese 1 (relação negativa entre o risco e o grau de alavancagem). No segundo estágio, a alavancagem é estimada usando os resultados do primeiro estágio, eliminando o problema de endogeneidadade do modelo. Com os resultados do segundo estágio, é possível confirmar as hipóteses 2 (relação positiva entre alavancagem e remuneração) e 3 (relação positiva entre intensidade do capital físico e remuneração).

A alavancagem é uma variável endógena no modelo de regressão que define a remuneração dos funcionários. Para resolver o problema de endogeneidade, foi utilizada uma regressão de dois estágios.

A primeira regressão para estimar alavancagem é:

$$
\begin{aligned}
\text { Alavancagem }_{i, t}= & \alpha_{0}+\alpha_{1} \text { Ano }_{t}+\alpha_{2} \text { Setor }_{i}+\alpha_{3} \text { Alavancagem }_{i, t-1}+ \\
& \alpha_{4} \text { AlMed }_{i, t-1}+\alpha_{5} \text { MTB }_{i, t-1}+\alpha_{6} \text { MIR }_{i, t-1}+\alpha_{7} \text { Ativo }_{i, t-1}+ \\
& \alpha_{8} \text { Lucra }_{i, t-1}+\alpha_{9} \text { ICF }_{i, t-1}+\alpha_{10} \text { VolRen }_{i, t-1}+ \\
& \alpha_{11} \text { ExPayout }_{i, t-1}+\delta_{i, t}
\end{aligned}
$$

Onde:

- $A n o_{t}$ - ano a que pertence a amostra;

- Setor $_{i}$ - setor a que pertence a empresa da amostra;

- Alavancagem $m_{, t 1}$ - alavancagem medida pela dívida total por capital total contábil no ano anterior;

- $\quad$ IMed $_{i, t 1}$ - alavancagem média do setor no anterior;

. MTB $_{i, t 1}$ - Market-to-book da empresa no ano anterior;

- $M I R_{, t 1}$ - alíquota média do imposto de renda corporativo nos últimos três exercícios do ano anterior;

. Ativo $_{i, t 1}$ - logaritmo do ativo total no anterior;

- Lucra $_{i, t 1}$ - rentabilidade medida como EBITDA sobre ativo total no ano anterior;

- $\quad I C F_{i, t 1}$ - intensidade do capital físico, medida como ativo imobilizado sobre ativo total no ano anterior;

- VolRen $_{i, t 1}$ - volatilidade da rentabilidade medida como o desvio padrão da rentabilidade nos últimos cinco exercícios no ano anterior;

- ExPayout $t_{i, t}$ - variável binária que indica se a empresa pagou mais do que $25 \%$ obrigatórios para os acionistas em forma de dividendos e juros sobre capital próprio.

Assim, a alavancagem é estimada pela equação (1) e é utilizada na equação (2) para estimar os parâmetros no modelo da remuneração média dos funcionários. O termo quadrado da alavancagem foi utilizado para compensar o efeito de não linearidade. A equação dois é a seguinte:

$$
\begin{aligned}
R M F_{i} & =\beta_{0}+\beta_{1} \text { Ano }_{t}+\beta_{2} \text { Setor }_{i}+\beta_{3} \text { Alavancagemhat }_{i, t}+\beta_{3} \text { Alavancagemhat }_{i, t}^{2} \\
& +\beta_{4} \text { Produtividade }_{i, t}+\beta_{5} \text { MTB }_{i, t}+\beta_{6} \text { ICF }_{i, t}+\beta_{7} \text { VolRen }_{i, t}+\varepsilon_{i, t}
\end{aligned}
$$

Onde: 
- $R M F_{i, t}$ - a remuneração média dos funcionários da empresa $i$ no ano $t$;

- Produtividade $_{i, t}$ - produtividade da empresa $i$ no ano $t$;

- Alavancagemhat ${ }_{i, t}$ - Alavancagem estimada na equação 1.

Para testar o modelo de Berk et al. (2010), que envolve um agente com aversão ao risco e um investidor com neutralidade ao risco, é necessário escolher o funcionário que possui o maior poder de decisão dentro da empresa: CEO. Escolher o CEO como proxy dos funcionários é também prático, pois não se pode obter o perfil de todos os funcionários da empresa, de acordo com Berk et al. (2010). Assim, é possível testar se a diferença na aversão ao risco dos trabalhadores resulta nas diferenças de alavancagem. Para testar esta hipótese, adotou-se o modelo que combina as características da empresa e as do CEO como variáveis explicativas de alavancagem. Desta forma, apresenta-se a equação 3.

$$
\begin{aligned}
\text { Alavancagem }_{i, t}= & \alpha_{0}+\alpha_{1} \text { Ano }_{t}+\alpha_{2} \cdot \text { Setor }_{i}+\alpha_{3} \text { Alavancagem }_{i, t-1}+\alpha_{4} \text { Ativo }_{i, t-1}+ \\
& \alpha_{5} \text { Lucra }_{i, t-1}+\alpha_{6} \text { ICF }_{i, t-1}+\alpha_{7} \operatorname{VolRen}_{i, t-1}+\alpha_{8} \text { IdadeCEO }_{i, t-1}+ \\
& \alpha_{9} \text { SexoCEO }_{i, t-1}+\alpha_{10} \text { EducaçãoCEO }_{i, t-1}+\alpha_{11} \text { MBACEO }_{i, t-1}+ \\
& \alpha_{12} \operatorname{Reputação~}_{i, t-1}+\delta_{i, t}
\end{aligned}
$$

Onde:

. IdadeCEO $O_{i, t 1}$ - idade do CEO da empesa $i$ no ano anterior;

. SexoCEO $O_{i, t 1}-$ sexo do CEO da empresa $i$ no ano anterior;

- EducaçãoCEO $O_{i, t 1}$ - nível educacional do CEO, expresso em anos de estudo, da empresa $i$ no ano anterior;

. MBACEO ${ }_{i, t 1}$ - indica se o CEO possui ou não MBA;

- Reputação ${ }_{i, t} 1$ - reputação da universidade onde o CEO se formou bacharel, expressa em Índice Geral de Cursos (IGC) do Ministério da Educação.

\section{Resultados e Análise dos Dados}

A Tabela 2 apresenta o resultado da regressão agrupada de mínimos quadrados (POLS) com erro padrão robusto (White, 1980). Pôde-se observar que alavancagem, tamanho, produtividade, intensidade do capital físico e volatilidade da rentabilidade são significantes. Entretanto, como a alavancagem é endógena, este resultado contém viés. 
Tabela 2

\section{OLS com Variáveis Explicativas da Remuneração}

\begin{tabular}{llc}
\hline Variáveis & \multicolumn{2}{l}{ Coeficiente (p-value) } \\
\hline Ano & \multicolumn{2}{l}{ Conjuntamente significante*** } \\
Setor & \multicolumn{2}{l}{ Conjuntamente significante*** } \\
Alavancagem & $1,246^{*}$ & $(0,097)$ \\
Alavancagem2 & $-1,35^{*}$ & $(0,088)$ \\
Tamanho (log do ativo) & $-0,102^{*}$ & $(0,084)$ \\
Produtividade & $0,002^{* * *}$ & $(0,000)$ \\
Market-to-book & 0,011 & $(0,308)$ \\
Intensidade do capital físico & $1,311^{* * *}$ & $(0,001)$ \\
Volatilidade da rentabilidade & $0,734^{* *}$ & $(0,05)$ \\
Intercepto & $4,568^{* * *}$ & $(0,000)$ \\
\hline Obs & 238 & \\
R2 ajustado & 0,576 & \\
\hline
\end{tabular}

Nota. Alavancagem é definida como a soma das dívidas de curto prazo e de longo prazo dividida pela soma das dívidas com o patrimônio líquido. Tamanho é definido como logaritmo do ativo total. Produtividade é definida como valor adicionado dividido pelo número de funcionários. Market-to-book é definida como valor da empresa no mercado dividido pelo patrimônio líquido. Intensidade do capital físico é definida como ativo imobilizado dividido pelo ativo total. Volatilidade da rentabilidade é definida como desvio padrão da rentabilidade de (EBIT) nos últimos cinco exercícios. Fonte: Elaborado pelos autores.

*, ** $\mathrm{e} * * *$ indicam significância de $10 \%, 5 \%$ e $1 \%$, respectivamente.

A Tabela 3 ilustra o resultado do primeiro estágio. Este estágio é usado para estimar a alavancagem que fará parte do modelo para estimar remuneração. Desta forma, elimina-se a endogeneidade. O primeiro estágio da regressão é apresentado de forma agrupada de dois estágios (Pooled 2SLS Regression) com erro padrão robusto (White, 1980). No modelo utilizado no estudo de Chemmanur et al. (2013), há uma predominância grande da alavancagem do ano anterior em relação às outras variáveis. Por este modelo não conseguir proporcionar resultados convincentes com dados brasileiros, optou-se pelo uso do modelo aqui denominado de modelo analisado, que não inclui a alavancagem do ano anterior.

No primeiro estágio, foi possível confirmar a primeira hipótese de que empresas com maior risco optam por alavancagem menor.

Tabela 3

\section{Resultados do Primeiro Estágio da Regressão}

\begin{tabular}{|c|c|c|}
\hline Variáveis & $\begin{array}{l}\text { Modelo (Chemmanur et al., } \\
\text { 2013) - p_valor }\end{array}$ & Modelo analisado - p_valor \\
\hline Ano & Conjuntamente significante $* * *$ & Conjuntamente significante* \\
\hline Setor & Conjuntamente significante $* * *$ & Conjuntamente significante ${ }^{* * *}$ \\
\hline Tamanho (defasado) & $-0,006 \quad(0,145)$ & $0,018^{* *} \quad(0,041)$ \\
\hline Alíquota de IR (defasada) & $0,005 \quad(0,447)$ & $(0,535)$ \\
\hline Alavancagem (defasada) & $0,896 * * *(0,000)$ & \\
\hline
\end{tabular}


Tabela 3 (continuação)

\begin{tabular}{|c|c|c|}
\hline Variáveis & $\begin{array}{c}\text { Modelo (Chemmanur et al., } \\
\text { 2013) - p_valor }\end{array}$ & Modelo analisado - p_valor \\
\hline Intensidade de capital físico (defasada) & $-0,057^{*} \quad(0,085)$ & $(0,467)$ \\
\hline Volatilidade da rentabilidade (defasada) & $(0,169)$ & $-2,249 * * *(0,000)$ \\
\hline Alavancagem média do setor (defasada) & $-0,220 \quad(0,123)$ & $0,038 \quad(0,879)$ \\
\hline Market-to-book (defasado) & $(0,416)$ & $0,010^{* * *} \quad(0,009)$ \\
\hline Rentabilidade (defasada) & $(0,760)$ & $-0,007 * * \quad(0,03)$ \\
\hline Pagamento de dividendos (defasado) & $(0,175)$ & $0,075^{* * *} \quad(0,003)$ \\
\hline Intercepto & $0,306^{* * *}(0,001)$ & $(0,276)$ \\
\hline Observações & \multicolumn{2}{|c|}{342} \\
\hline R-quadrado & 0,821 & 0,332 \\
\hline
\end{tabular}

Nota. Tamanho defasado é definido como o logaritmo do ativo total no ano anterior. Alíquota de IR defasada é definida como o imposto pago dividido pelo lucro líquido antes do imposto de renda no ano anterior. Alavancagem defasada é definida como a soma das dívidas de curto e de longo prazo dividida pela soma das dívidas com o patrimônio líquido no ano anterior. Intensidade do capital físico defasada é definida como o ativo imobilizado dividido pelo ativo total no ano anterior. Volatilidade da rentabilidade defasada é definida como o desvio padrão da rentabilidade de EBIT nos últimos cinco exercícios no ano anterior. Market-to-book defasada é definida como o valor da empresa no mercado dividido pelo patrimônio líquido. Rentabilidade defasada é definida como EBITDA dividida pelo ativo total no anterior. Pagamento de dividendos é definido como 1, se a empresa pagou mais do que $25 \%$ do lucro líquido no anterior, e 0, se pagou abaixo de $25 \%$. Fonte: Elaborado pelos autores a partir de Chemmanur, T. J., Cheng, Y., \& Zhang, T. (2013). Human capital, capital structure, and employee pay: an empirical analysis. Journal of Financial Economics, 110(2), 478-502. doi: 10.1016/j.jfineco.2013.07.003. $*, * * \mathrm{e} * * *$ indicam significância de $10 \%, 5 \%$ e $1 \%$, respectivamente.

Conforme Bradley, Jarrel e Kim (1984), é esperado que a volatilidade da rentabilidade, proxy do risco de negócio, tenha uma relação negativa com o grau de endividamento, o que é condizente com o resultado deste estudo. A razão Market-to-book é considerada uma proxy do potencial de crescimento da empresa. É aceitável que este potencial de crescimento pudesse apresentar relação negativa com alavancagem (Rajan \& Zingales, 1995), pois empresas com mais oportunidade de investimento reservariam sua capacidade de empréstimo. No entanto o estudo empírico de Chen e Zhao (2006) mostra que, para a maioria das empresas americanas, esta relação é positiva. A explicação é de que quanto maior for esta razão, mais baixo é o custo do empréstimo. Portanto, empresas aumentam a alavancagem de acordo com o aumento da razão, condizente com o resultado deste estudo.

Como a intensidade de capital físico também representa tangibilidade, ela proporciona uma capacidade de empréstimo maior. Rajan e Zingales (1995), na pesquisa com os países do G7, encontraram uma relação positiva entre tangibilidade e alavancagem. Para as empresas americanas, no período entre 1950 e 2003, Frank e Goyal (2009) também encontraram uma relação positiva entre estas varáveis. No Brasil, alguns estudos (Brito \& Lima, 2005; Rocha \& Amaral, 2007) individuaram relação positiva, enquanto outros (Bastos et al., 2009; Medeiros \& Daher, 2005) indicaram relação negativa. O resultado desta regressão não é conclusivo, pois não é estatisticamente significante, embora seja positivo.

A rentabilidade do ano anterior apresentou relação negativa com a alavancagem do ano atual de análise, e é estatisticamente significante. Isso pode ser uma prova da existência de pecking order (S. C. Myers \& Majluf, 1984) nas empresas brasileiras, corroborando trabalhos anteriores. A variável que mostra se a empresa pagou o excesso de dividendos ou não durante o ano anterior revelou ser significante e positiva, provando a existência do mecanismo de substituição entre dívida e dividendos (Agrawal \& Jayaraman, 1994; Jensen, 1986) nas empresas brasileiras.

Utilizando o resultado do primeiro estágio, é possível estimar a alavancagem, e esta estimativa foi utilizada para executar o segundo estágio da regressão. Na Tabela 4, apresenta-se o resultado do segundo estágio da regressão agrupada de dois estágios (Pooled 2SLS Regression) com erro padrão 
robusto (White, 1980). O resultado evidencia que a alavancagem está positivamente relacionada com remuneração, o que foi previsto no modelo de Berk et al. (2010), confirmando a hipótese 2. Para calcular o efeito do aumento da alavancagem sobre remuneração, executou-se uma simulação com a mediana da alavancagem (veja Apêndice). De acordo com este resultado, 26\% do aumento da alavancagem são repassados para a remuneração. Em outras palavras, se a alavancagem aumenta 10\%, haverá um aumento de 2,6\% na remuneração dos funcionários. Este número é bastante significativo, se comparado com a própria alíquota de imposto de renda corporativo (15\% de IRPJ e 9\% de CSLL, resultando em torno de $24 \%$ do imposto pago sobre lucro líquido).

Tabela 4

\section{Resultados do Segundo Estágio da Regressão}

\begin{tabular}{|c|c|c|}
\hline Variáveis & $\begin{array}{c}\text { Modelo (Chemmanur et al., 2013) - } \\
\text { p_valor }\end{array}$ & Modelo Analisado - p_valor \\
\hline Ano & Conjuntamente significante $* * *$ & Conjuntamente significante $* * *$ \\
\hline Setor & Conjuntamente significante $* * *$ & Conjuntamente significante ${ }^{* * *}$ \\
\hline Alavancagem & $0,868 \quad(0,528)$ & $3,886^{* *}$ \\
\hline Alavancagem 2 & $-0,748 \quad(0,621)$ & $-4.031 * * \quad(0,039)$ \\
\hline Tamanho & $-0,144 * * \quad(0,015)$ & $-0,170 * * * \quad(0,006)$ \\
\hline Produtividade & $0,002 * * *(0,000)$ & $0,002 * * * \quad(0,000)$ \\
\hline Market-to-Book & $0,008 \quad(0,56)$ & $0,024 *$ \\
\hline Intensidade do capital físico & $1,360 * * *(0,002)$ & $1,144 * * * \quad(0,006)$ \\
\hline Volatilidade da rentabilidade & $3,127 * * \quad(0,034)$ & $(0,028)$ \\
\hline Intercepto & $4,348 * * *(0,000)$ & $4,010 * * * \quad(0,000)$ \\
\hline
\end{tabular}

Observações

203

R2 Ajustado

0,600

0,573

Nota. Alavancagem é definida como a soma das dívidas de curto prazo e de longo prazo dividida pela soma das dívidas com o patrimônio líquido. Tamanho é definido como logaritmo do ativo total. Produtividade é definida como o valor adicionado dividido pelo número de funcionários. Market-to-book é definido como o valor da empresa no mercado dividido pelo patrimônio líquido. Intensidade do capital físico é definido como o ativo imobilizado dividido pelo ativo total. Volatilidade da rentabilidade é definida como o desvio padrão da rentabilidade de EBIT nos últimos cinco exercícios. Fonte Elaborado pelos autores a partir de Chemmanur, T. J., Cheng, Y., \& Zhang, T. (2013). Human capital, capital structure, and employee pay: an empirical analysis. Journal of Financial Economics, 110(2), 478-502. doi: 10.1016/j.jfineco.2013.07.003.

$*, * * \mathrm{e} * * *$ indicam significância de $10 \%, 5 \%$ e $1 \%$, respectivamente.

O resultado do segundo estágio da regressão também confirma a hipótese 3: uma empresa mais intensiva em capital possui maior alavancagem e paga maior remuneração, explicação realizada pelo modelo de Berk et al. (2010), que prevê este resultado por causa da diminuição ex-ante do endividamento das empresas intensivas em trabalho. Contudo existem outras explicações para este resultado. A primeira é a hipótese de complementaridade entre capital e habilidade (Bergström \& Panas, 1992). Uma empresa intensiva em capital exige capital humano mais qualificado, o que aumentaria a remuneração. A segunda explicação está relacionada ao fato de uma empresa intensiva em capital estar mais vulnerável à greve (Viren, 2006). Uma empresa intensiva em capital apresenta custo fixo muito alto e ela poderia sofrer mais do que as empresas mais intensivas em trabalho, caso houvesse uma greve. Assim, a empresa ficaria em desvantagem em relação ao sindicato quando negocia o salário dos trabalhadores, resultando na remuneração mais alta.

No que diz respeito à ótica da economia do trabalho, esta pode ser uma explicação para a alavancagem mais alta das empresas (B. W. Myers \& Saretto, 2011; Matsa, 2010; Perotti \& Spier, 1993). Segundo esses autores, as empresas aumentariam a alavancagem financeira para diminuir a liquidez 
financeira e ter uma posição privilegiada na hora de negociar com os sindicatos. Ou seja, uma empresa mais intensiva em capital, por estar em desvantagem na hora de negociar com os sindicatos, aumentaria a alavancagem para aumentar o poder de barganha. O sinal negativo e estatisticamente significante da volatilidade da rentabilidade prova que as empresas com maior risco de negócio remuneram melhor os seus funcionários. A volatilidade da rentabilidade representa o risco de negócio que as empresas enfrentam e está ligada à remuneração variável e à probabilidade de ajuste no quadro funcional. Junto ao sinal positivo da alavancagem, este resultado ajuda a reforçar a confirmação da hipótese 2.

A variável produtividade se revela estatisticamente significante e passa nos testes de robustez, o que pode ser observado na Tabela 5. Este resultado confirma a teoria da economia de trabalho, visto que remuneração está ligada à produtividade do trabalhador, embora a produtividade seja resultado de vários fatores, não apenas do trabalho dos colaboradores. Um resultado interessante é o sinal negativo do tamanho da empresa. É provável que produtividade, tamanho e remuneração estejam positivamente relacionados (Miller, 1978; Oi \& Idson, 1999). No entanto, quando se mede a saída do trabalho como valor adicionado, esta relação é negativa. Para testar a robustez da significância da alavancagem, a medida de alavancagem inicial foi substituída por diferentes medidas. A Tabela 5 apresenta o resultado do segundo estágio da regressão agrupado de dois estágios (Pooled 2SLS Regression) com erro padrão robusto (White, 1980).

Tabela 5

\section{Resultado do Teste de Robustez}

\begin{tabular}{|c|c|c|c|c|c|c|}
\hline \multicolumn{3}{|c|}{ Variáveis } & \multicolumn{4}{|c|}{ Coeficientes (valor $\mathbf{p}$ ) } \\
\hline Ano & \multicolumn{2}{|c|}{$\begin{array}{l}\text { Conjuntamente } \\
\text { significante* }\end{array}$} & \multicolumn{2}{|c|}{$\begin{array}{l}\text { Conjuntamente } \\
\text { significante* }\end{array}$} & \multicolumn{2}{|c|}{$\begin{array}{l}\text { Conjuntamente } \\
\text { significante* }\end{array}$} \\
\hline Setor & \multicolumn{2}{|c|}{$\begin{array}{l}\text { Conjuntamente } \\
\text { significante*** }\end{array}$} & \multicolumn{2}{|c|}{$\begin{array}{l}\text { Conjuntamente } \\
\text { significante*** }\end{array}$} & \multicolumn{2}{|c|}{$\begin{array}{l}\text { Conjuntamente } \\
\text { significante } * * *\end{array}$} \\
\hline Alavancagem BVE & 0,053 & $(0,613)$ & & & & \\
\hline Alavancagem BVE2 & $-0,001$ & $(0,554)$ & & & & \\
\hline Alavancagem AT & & & $7,265 * *$ & $(0,042)$ & & \\
\hline Alavancagem AT2 & & & $-9,812 * *$ & $(0,046)$ & & \\
\hline Alavancagem MT & & & & & 4,525 & $(0,251)$ \\
\hline Alavancagem MT2 & & & & & $-5,873$ & $(0,275)$ \\
\hline Tamanho & $-0,138 * *$ & $(0,013)$ & $-0,205^{* * *}$ & $(0,006)$ & $-0,180 * * *$ & $(0,009)$ \\
\hline Produtividade & $0,002 * * *$ & $(0,000)$ & $0,002 * * *$ & $(0,000)$ & $0,002 * * *$ & $(0,000)$ \\
\hline Market-to-Book & $-0,001$ & $(0,998)$ & 0,005 & $(0,678)$ & 0,009 & $(0,434)$ \\
\hline $\begin{array}{l}\text { Intensidade do capital } \\
\text { físico }\end{array}$ & $1,403 * * *$ & $(0,003)$ & $0,981 * *$ & $(0,024)$ & $1,127 * *$ & $(0,014)$ \\
\hline $\begin{array}{l}\text { Volatilidade da } \\
\text { rentabilidade }\end{array}$ & $2,944 *$ & $(0,092)$ & $4,937 * *$ & $(0,044)$ & $4,312 *$ & $(0,057)$ \\
\hline Intercepto & $4,489 * * *$ & $(0,000)$ & $4,176^{* * *}$ & $(0,000)$ & $4,362 * * *$ & $(0,000)$ \\
\hline Observações & 20 & & 20 & & 20 & \\
\hline R2 Ajustado & 0,5 & & 0,5 & & 0,47 & \\
\hline
\end{tabular}

Nota. Alavancagem BVE é definida como a soma das dívidas de curto prazo e de longo prazo dividida pelo patrimônio líquido. Alavancagem AT é definida como a soma das dívidas de curto e de longo prazo dividida pelo ativo total. Alavancagem MT é definida como a soma das dívidas de curto e de longo prazo dividida por (ativo total - patrimônio líquido + valor da empresa no mercado). Tamanho é definido como logaritmo do ativo total. Produtividade é definida como o valor adicionado dividido pelo número de funcionários. Market-to-book é definida como o valor da empresa no mercado dividido pelo patrimônio líquido. Intensidade do capital físico é definida como o ativo imobilizado dividido pelo ativo total. Volatilidade da rentabilidade é definida como o desvio padrão da rentabilidade de EBIT nos últimos cinco exercícios. Fonte: Elaboração própria. $*, * *$ e *** indicam significância de $10 \%, 5 \%$ e $1 \%$, respectivamente. 
O teste mostra que para as três medidas de alavancagens usadas, apenas uma se mostra significante. Todas as outras variáveis (tamanho, produtividade, intensidade do capital físico e volatilidade da rentabilidade), que se mostraram significantes no primeiro modelo, também se mostraram significantes neste segundo, comprovando sua robustez.

A Tabela 6 apresenta os resultados da regressão agrupados de mínimos quadrados com as características das empresas e dos CEOs, com erro padrão robusto (White, 1980).

Tabela 6

\section{Regressão para Alavancagem com as Características da Empresa e do CEO}

\begin{tabular}{|c|c|}
\hline Variáveis & Coeficiente (valor $\mathbf{p}$ ) \\
\hline$\overline{A n o}$ & Não significante \\
\hline Setor & Conjuntamente significante ${ }^{* * *}$ \\
\hline Tamanho (defasado) & $0,07^{* * *} \quad(0,000)$ \\
\hline Market-to-book (defasado) & $0,010^{* * *}(0,008)$ \\
\hline Intensidade de capital físico (defasada) & $0,288^{*} \quad(0,086)$ \\
\hline Rentabilidade (defasada) & $-0,500 * * \quad(0,018)$ \\
\hline Volatilidade da rentabilidade (defasada) & $-1,382^{* *} \quad(0,039)$ \\
\hline Idade de CEO (defasada) & $-0,006^{* * *}(0,006)$ \\
\hline Gênero de CEO (defasado) & $-0,022 \quad(0,752)$ \\
\hline Educação de CEO (defasado) & $(0,755)$ \\
\hline MBA (defasado) & $-0,053 \quad(0,361)$ \\
\hline Reputação da escola (defasada) & $0,0001 * *(0,016)$ \\
\hline Intercepto & $-0,421$ \\
\hline Observações & 229 \\
\hline $\mathrm{R} 2$ ajustado & 0,549 \\
\hline
\end{tabular}

Nota. Tamanho defasado é definido como o logaritmo do ativo total no ano anterior. Alíquota de IR defasada é definida como o imposto pago dividido pelo lucro líquido antes do imposto de renda do ano anterior. Alavancagem defasada é definida como a soma das dívidas de curto e de longo prazo dividida pela soma das dívidas com o patrimônio líquido no ano anterior. Intensidade do capital físico defasada é definida como o ativo imobilizado dividido pelo ativo total no ano anterior. Volatilidade da rentabilidade defasada é definida como o desvio padrão da rentabilidade do EBIT nos últimos cinco exercícios no ano anterior. Market-to-book defasado é definido como o valor da empresa no mercado dividido pelo patrimônio líquido. Rentabilidade defasada é definida como EBITDA dividida pelo ativo total no anterior. Idade do CEO defasada é definida como a idade do CEO no ano anterior. Educação do CEO no ano anterior é definida como anos de estudo do CEO no ano anterior. $M B A$ é definido como 1 se o CEO fez MBA, 0, caso contrário. Reputação da escola é definida pelo IGC da instituição onde o CEO obteve o título de bacharel. Fonte: Elaboração Própria.

*, ** e *** indicam significância de $10 \%, 5 \%$ e $1 \%$, respectivamente.

O resultado mostra que a idade do CEO está negativamente relacionada ao grau de alavancagem. Já a reputação da escola está positivamente relacionada a esse nível. Em outras palavras, a estrutura de capital é mais conservadora para CEO de mais idade e mais agressiva para CEO que estudou em instituição de melhor reputação. Esse resultado, mesmo indiretamente, confirma a hipótese 4, de que a diferença na aversão ao risco dos funcionários resulta em diferença na alavancagem.

O resultado desta pesquisa corrobora os estudos realizados sobre os determinantes de aversão ao risco (Jianakoplos \& Bernasek, 1998; Morin \& Suarez, 1983; Palsson, 1996) e sobre a relação entre as características individuais de executivos e a estrutura de capital da empresa, apresentada por Graham et al. (2012). O efeito da alavancagem sobre a remuneração pode ter outras explicações que não foram consideradas no modelo e, desta forma, afetar positivamente tanto a alavancagem quanto a remuneração. 
Este problema poderia ser resolvido utilizando regressão em painel com efeito fixo. No entanto, pela escassez de dados, no momento, não foi possível aplicar este método.

\section{Conclusão}

Este trabalho testou como o custo causado pelas pessoas nas empresas pode afetar a estrutura de capital destas. O resultado empírico revela que esse custo é bastante relevante para ser ignorado. Para o aumento de $1 \%$ na alavancagem, haverá um aumento de $0,26 \%$ na remuneração dos funcionários, no caso de uma empresa típica. Dependendo da empresa, este aumento pode ser superior ao benefício fiscal. Verificou-se, também, uma relação positiva entre intensidade física e remuneração. Este resultado pode ser explicado através do modelo de Berk et al. (2010), mas a economia do trabalho pode oferecer explicações bastante interessantes em adição ao que foi apresentado pelos pesquisadores. A abordagem de finanças corporativas poderia explicar este resultado, para tanto, focando na tangibilidade dos ativos imobilizados e na reação preventiva ao aumento do custo de trabalho pelas empresas com alto custo advindo do trabalho. A economia do trabalho poderia explicar o mesmo resultado focando na complementaridade entre capital e habilidade e a suscetibilidade quanto a greve das empresas intensivas em capital.

O estudo com as características dos CEOs mostra que a política da empresa é afetada pelo perfil da pessoa que a dirige, já que se pôde observar que os determinantes da aversão ao risco também são os determinantes da alavancagem da empresa.

O trabalho indica resultado positivo a respeito da ligação entre a estrutura de capital e o custo do capital humano, porém apresenta algumas limitações. A primeira delas é a aplicabilidade. O estudo cobre um período bastante pequeno (três anos) e uma amostra pequena de empresas. Isso se deve ao fato de que os relatórios que fornecem esses dados ainda são muito recentes. É preciso ressaltar que a divulgação desses dados se tornou obrigatória recentemente (Deliberação CVM n. 557, 2008). No entanto, com o passar do tempo, haverá disponibilidade maior de dados, o que vai possibilitar uma análise mais robusta do modelo.

O efeito da alavancagem sobre a remuneração pode ter outras explicações que não foram consideradas no modelo e, assim, afetar positivamente tanto a alavancagem quanto a remuneração. Este problema seria resolvido utilizando regressão em painel com efeito fixo, o que não foi possível neste estudo. Em adição, partiu-se do pressuposto de que há relação entre o perfil da pessoa e a aversão ao risco. Desta forma, outra análise que poderia comprovar essa ligação seria medir a aversão ao risco diretamente, utilizando-se testes psicométricos. Somente através destes testes a hipótese 4 poderá ser comprovada diretamente.

Foram observados vários fatos interessantes que levariam para uma pesquisa futura, como a relação de intensidade do capital físico, estrutura de capital e a remuneração. Seria interessante investigar como a teoria econômica pode explicar os resultados obtidos neste estudo, no Brasil, onde o poder dos sindicatos é grande, além da vasta diferença no mercado de trabalho e de fatores macroeconômicos completamente diferentes.

\section{Referências}

Agrawal, A., \& Jayaraman, N. (1994). The dividend policies of all-equity firms: a direct test of the free cash flow theory. Managerial and Decision Economics, 15(2), 139-148. doi: 10.1002/mde.4090150206 
Almeida, H., \& Philippon, T. (2007). The risk-adjusted cost of financial distress. The Journal of Finance, 62(6), 2557-2586. doi: 10.3386/w11685

Balassiano, M., Seabra, A. A. de, \& Lemos, A. H. (2005). Escolaridade, salários e empregabilidade: tem razão a teoria do capital humano? Revista de Administração Contemporânea, 9(4), 31-52. doi: $10.1590 / \mathrm{S} 1415-65552005000400003$

Bastos, D. D., Nakamura, W. T., \& Basso, L. F. C. (2009). Determinantes da estrutura de capital das companhias abertas na América Latina: um estudo empírico considerando fatores macroeconômicos e institucionais. Revista de Administração Mackenzie, 10(6), 47-77.

Becker, G. (1964). Human capital. Chicago: University of Chicago, Press.

Bergström, V., \& Panas, E. E. (1992). How robust is the capital-skill complementarity hypothesis? The Review of Economics and Statistics, 74(3), 540-546.

Berk, J. B., Stanton, R., \& Zechner, J. (2010). Human capital, bankruptcy, and capital structure. The Journal of Finance, 65(3), 891-926. doi: 10.1111/j.1540-6261.2010.01556.x

Bradley, M., Jarrel, G. A., \& Kim, E. H. (1984). On the existence of an optimal capital structure: theory and evidence. The Journal of Finance, 39(3), 857-878. doi: 10.1111/j.1540-6261.1984.tb03680.x

Brito, R. D., \& Lima, M. R. (2005). A escolha da estrutura de capital sob fraca garantia legal: o caso do Brasil. Revista Brasileira de Economia, 59(2), 177-208. doi: 10.1590/S003471402005000200002

Chang, C. (1992). Capital structure as an optimal contract between employees and investors. The Journal of Finance, 47(3), 1141-1158. doi: 10.1111/j.1540-6261.1992.tb04008.x

Chang, C. (1993). Payout policy, capital structure, and compensation contracts when managers value control. Review of Financial Studies, 6(4), 911-933. doi: 10.1093/rfs/6.4.911

Chemmanur, T. J., Cheng, Y., \& Zhang, T. (2013). Human capital, capital structure, and employee pay: an empirical analysis. Journal of Financial Economics, 110(2), 478-502. doi: 10.1016/j.jfineco.2013.07.003

Chen, L., \& Zhao, X. (2006). On the relation between the market-to-book ratio, growth opportunity, and leverage ratio. Finance Research Letters, 3(4), 253-266. doi: 10.1016/j.frl.2006.06.003

Deliberação CVM n. 557, de 12 de Novembro de 2008. (2008). Aprova o pronunciamento técnico cpc 09 do comitê de pronunciamentos contábeis, que trata da demonstração do valor adicionado. Recuperado http://www.cvm.gov.br/asp/cvmwww/atos/Atos_Redir.asp?Tipo=D\&File=/delildeli557.doc

Ehrenberg, R. G. (1989). Workers' compensation, wages and the risk of injury. [Working Paper $n^{\circ}$ 1538]. National Bureau of Economic Research, Cambridge, MA.

Ehrlich, I., Hamlem, W., Jr., \& Yin, Y. (2008). Asset management, human capital, and the market for risky assets [Working Paper $n^{\circ}$ 14340]. National Bureau of Economic Research, Cambridge, MA.

Esteves, L. A. (2008a). Risk of firm closure and wages in Brazil: compensating wage diferentials or bargaining concessions? (Trabalho não publicado). Departamento de Economia, Universidade Federal do Paraná, Curitiba, PR, Brasil.

Esteves, L. A. (2008b). Salários e risco de acidentes de trabalho: evidências de diferenciais compensatórios para a indústria manufatureira. Economia Aplicada, 12(2), 275-287. doi: 10.1590/S1413-80502008000200005 
Fama, E. F., \& French, K. R. (1998). Taxes, financing decisions, and firm value. The Journal of Finance, 53(3), 819-843. doi: 10.1111/0022-1082.00036

Fama, E. F., \& French, K. R. (2002). Testing trade-off and pecking order predictions about dividends and debt. Review of Financial Studies, 15(1), 1-33. doi: 10.1093/rfs/15.1.1

Frank, M. Z., \& Goyal, V. K. (2009). Capital structure decisions: which factors are reliably important? Financial Management, 38(1), 1-37. doi: 10.1111/j.1755-053X.2009.01026.x

Gatica, J., Mizala, A., \& Romaguera, P. (1995). Interindustry wage differentials in Brazil. Economic Development and Cultural Change, 43(2), 315-331.

Gomes, G. L., \& Leal, R. P. C. (2001). Determinantes da estrutura de capital das empresas brasileiras com ações negociadas em bolsas de valores. In R. P. C. Leal (Org.), Finanças corporativas (Cap. 3, pp. 42-56). São Paulo: Atlas.

Graham, J. R. (1996). Debt and the marginal tax rate. Journal of Financial Economics, 41(1), 41-73. doi: 10.1016/0304-405X(95)00857-B

Graham, J. R. (2000). How big are the tax benefits of debt? The Journal of Finance, 55(5), 1901-1941. doi: 10.1111/0022-1082.00277

Graham, J. R., Harvey, C. R., \& Puri, M. (2012). Managerial attitudes and corporate actions. Retrieved from http://papers.ssrn.com/sol3/papers.cfm?abstract_id=1432641

Hiramoto, E., \& Saito, R. (2010). Foreign activity effects on the capital structure of Brazilian companies during. Academia - Revista Latinoamericana de Administración, 45, 59-75.

Hryshko, D., Luengo-Prado, M. J., \& Sorensen, B. E. (2008). Childhood determinants of risk aversion: the long shadow of compulsory education. Retrieved from http://www.uh.edu/ bsorense/RAdec16_2010bb.pdf

Idson, T. L., \& Oi, W. Y. (1999). Workers are more productive in large firms. American Economic Review, 89(2), 104-108. doi: 10.1257/aer.89.2.104

Jaggia, P. B., \& Thakor, A. V. (1994). Firm-specific human capital and optimal capital structure. International Economic Review, 35(2), 283-308.

Jensen, M. C. (1986). Agency costs of free cash flow, corporate finance, and takeovers. American Economic Review, 76(2), 323-29. doi: 10.2139

Jianakoplos, N. A., \& Bernasek, A. (1998). Are women more risk averse? Economic Inquiry, 36(4), 620-630. doi: 10.1111/j.1465-7295.1998.tb01740.x

Kayo, E. K., \& Famá, R. (1997). Teoria de agência e crescimento: evidências empíricas dos efeitos positivos e negativos do endividamento. Caderno de Pesquisa em Administração, 2(5), 1-8.

Lei $n^{o}$. 6.404, de 15 de dezembro de 1976. (1976). Dispõe sobre as sociedades por ações. Brasília. Recuperado de http://www.planalto.gov.br/ccivil_03/leis/16404consol.htm

Lei $n^{o}$. 9.249, de 26 de dezembro de 1995. (1995). Altera a legislação do imposto de renda das pessoas jurídicas, bem como da contribuição social sobre o lucro líquido, e dá outras providências. Brasília. http://www.receita.fazenda.gov.br/Legislacao/leis/Ant2001/lei924995.htm

Lemmon, M. L., Roberts, M. R., \& Zender, J. F. (2008). Back to the beginning: persistence and the cross-section of corporate capital structure. The Journal of Finance, 63(4), 1575-1608. doi: 10.1111/j.1540-6261.2008.01369.x 
Linn, M. W., Sandifer, R., \& Stein, S. (1985). Effects of unemployment on mental and physical health. American Journal of Public Health, 75(5), 502-506. doi: 10.2105/AJPH.75.5.502

Masters, S. H. (1969). An interindustry analysis of wages and plant size. The Review of Economics and Statistics, 51(3), 341-345.

Matsa, D. A. (2010). Capital structure as a strategic variable: evidence from collective bargaining. Journal of Finance, 65(3), 1197-1232. doi: 10.1111/j.1540-6261.2010.01565.x

Matsuo, A. K., Rochman, R. R., \& Eid, W., Jr. (2008). Estrutura de capital no Brasil: uma revisão teórica dos estudos de 1988 até 2005. In R. Saito \& J. L. Procianoy (Orgs.), Captação de recursos de longo prazo (Cap. 3, pp. 69-95). São Paulo: Atlas.

Medeiros, O. R., \& Daher, C. E. (2005). Testando a teoria de hierarquização de fontes de financiamento nas empresas brasileiras. Revista de Contabilidade e Finanças, 16(37), 37-45. doi: 10.1590/S1519-70772005000100003

Miller, E. M. (1978). The extent of economies of scale: the effects of firm size on labor productivity and wage rates. Southern Economic Journal, 44(3), 470-487.

Modigliani, F., \& Miller, M. H. (1958). The cost of capital, corporation finance and the theory of investment. American Economic Review, 48(3), 261-297.

Morin, R.-A., \& Suarez, A. F. (1983). Risk aversion revisited. Journal of Finance, 38(4), 1201-1216. doi: 10.1111/j.1540-6261.1983.tb02291.x

Myers, B. W., \& Saretto, A. (2011). Leverage and the interaction between firms and non-financial stakeholders: evidence from contract negotiations and union strikes [Working Papers Series]. Social Science Research Network. Retrieved from http://papers.ssrn.com/sol3/papers.cfm?abstract_id=1907940

Myers, S. C. (1977). Determinants of corporate borrowing. Journal of Financial Economics, 5(2), 147175. doi: 10.1016/0304-405X(77)90015-0

Myers, S. C. (1984). The capital structure puzzle. Journal of Finance, 39(3), 575-592. doi: 10.1111/j.1540-6261.1984.tb03646.x

Myers, S. C., \& Majluf, N. S. (1984). Corporate financing and investment decisions when firms have information that investors do not have. Journal of Financial Economics, 13(2), 187-221. doi: 10.1016/0304-405X(84)90023-0

Nakamura, W. T., Martin, D. M. L., Forte, D., Carvalho, A. F., Filho, Costa, A. C. F. da, \& Amaral, A. C. do (2007). Determinantes de estrutura de capital no mercado brasileiro - análise de regressão com painel de dados no período 1999-2003. Revista Contabilidade e Finanças, 18(44), 72-85. Recuperado de http://www.scielo.br/pdf/rcf/v18n44/a07v1844.pdf. doi: 10.1590/S151970772007000200007

Novaes, W., \& Zingales, L. (1995). Capital structure choice when managers are in control: entrenchment versus efficiency [Working Paper $\mathrm{N}^{\circ}$ 5384]. National Bureau of Economic Research, Cambridge, MA.

Oi, W. Y., \& Idson, T. L. (1999). Firm size and wages. In O. Ashenfelter \& D. Card (Eds.), Handbook of labor economics (Vol. 3, Chap. 33, pp. 2165-2214). New York: Elsevier.

Palsson, A.-M. (1996). Does the degree of relative risk aversion vary with household characteristics? Journal of Economic Psychology, 17(6), 771-787. doi: 10.1016/S0167-4870(96)00039-6 
Perotti, E. C., \& Spier, K. E. (1993). Capital structure as a bargaining tool: the role of leverage in contract renegotiation. American Economic Review, 83(5), 1131-1141.

Rajan, R. G., \& Zingales, L. (1995). What do we know about capital structure? Some evidence from international data. Journal of Finance, 50(5), 1421-60. doi: 10.1111/j.1540-6261.1995.tb05184.x

Rocha, F. D., \& Amaral, H. F. (2007, julho). Análise dos determinantes do endividamento das empresas brasileiras à luz de abordagens teóricas tradicionais e recentes. Anais do Encontro Brasileiro de Finanças, São Paulo, SP, Brasil, 7.

Silva, J. C. G. da, \& Brito, R. D. (2005). Testando as previsões de trade-off e pecking order sobre dividendos e dívida no Brasil. Estudos Econômicos, 35(1), 37-79. doi: 10.1590/S010141612005000100002

Silveira, A. D. M., Perobelli, F. F. C., \& Barros, L. A. B. C. (2008). Governança corporativa e os determinantes da estrutura de capital: evidências empíricas no Brasil. Revista de Administração Contemporânea, 12(3), 763-788. doi: 10.1590/S1415-65552008000300008

Terra, P. R. S. (2002, setembro). An empirical investigation on the determinants of capital structure in Latin America. Anais do Encontro Nacional da Associação Nacional de Pós-Graduação e Pesquisa em Administração, Salvador, BA, Brasil, 26.

Titman, S. (1984). The effect of capital structure on a firm's liquidation decision. Journal of Financial Economics, 13(1), 137-151. doi: 10.1016/0304-405X(84)90035-7

Titman, S., \& Wessels, R. (1988). The determinants of capital structure choice. Journal of Finance, 43(1), 1-19. doi: 10.1111/j.1540-6261.1988.tb02585.x

Viren, M. (2006). Higher wages and capital intensity: a closer look [Discussion Paper n. 13]. Aboa Centre for Economics. Retrieved from http://www.aceeconomics.fi/kuvat/ACE13\%20Viren\%20valmis.pdf

Viscusi, W. K. (1978). Wealth effects and earnings premiums for job hazards. Review of Economics and Statistics, 60(3), 408-416.

Weiss, L. A. (1990). Bankruptcy resolution: direct costs and violation of priority of claims. Journal of Financial Economics, 27(2), 285-314. doi: 10.1016/0304-405X(90)90058-8

White, H. A. (1980). Heteroskedasticity-consistent covariance matrix estimator and a direct test for heteroskedasticity. Econometrica, 48(4), 817-38.

\section{Dados dos Autores}

Duk Young Choi

Rua Itapeva, 432, 01332-000, Bela Vista, São Paulo, SP, Brasil. E-mail: choi.duk@ gmail.com

Richard Saito

Rua Itapeva, 432, 01332-000, Bela Vista, São Paulo, SP, Brasil. E-mail: richard.saito@ fgv.br

Vinicius Augusto Brunassi Silva

Rua Itapeva, 432, 01332-000, Bela Vista, São Paulo, SP, Brasil. E-mail: vinicius.brunassi@ gvmail.br 


\section{APÊNDICE}

\section{Cálculo do Efeito Alavancagem sobre Remuneração}

Mediana da alavancagem $=0,467$

Coeficiente $_{,, 467}=3,89 \times 0,467 \quad 4,03 \times 0,467^{2}=0,938$

Quando se supõe que a alavancagem aumente $1 \%($ Alavancagem $=1 \%)$,

Alavancagem $_{2}=0,477$

Coeificiente $_{,, 477}=3,389 \times 0,477 \quad 4,03 \times 0,477^{2}=0,939$

O efeito sobre a remuneração é:

$$
\begin{aligned}
& \text { Remuneração }=e^{0,939} \quad e^{0,938}=0,0026 \\
& \frac{\text { Remuneração }}{\text { Alavancagem }}=\frac{0,0026}{0,01}=26 \%
\end{aligned}
$$

